\title{
Effects of Supplementary Vitamin D on Vitamin D3 Serum Level in Nephrotic Syndrome Patients Receiving Steroid Therapy
}

\author{
Hashem Mahmoodzadeh $^{1 \oplus}$, Mohammad Valizadeh $^{2 *}{ }^{*}$, Ahmadali Nikibakhsh $^{3}$, Ezatollah Abbasi ${ }^{4}$ \\ ${ }^{1}$ Associate Professor of Pediatric Nephrology, Shahid Motahari Hospital, Urmia University of Medical Sciences, Urmia, Iran \\ ${ }^{2}$ Department of Pediatrics, Shahid Motahari Hospital, Urmia University of Medical Sciences, Urmia, Iran \\ ${ }^{3}$ Professor of Pediatric Nephrology, Urmia University of Medical Sciences, Urmia, Iran \\ ${ }^{4}$ Assistant Professor of Pediatric Neurology, Urmia University of Medical Sciences, Urmia, Iran
}

*Correspondence to

Mohammad Valizadeh,

Tel:00989144965734,

Email : mohammadkv1353@gmail. com

Received November 29, 2020 Accepted December 25, 2020 Published online December 30, 2020

\begin{abstract}
Introduction: Nephrotic syndrome is one of the most common glomerular diseases in children who are also at risk of metabolic bone diseases. In this study the effect of supplementary use of vitamin D3 was assessed on serum levels of vitamin D3 in patients with nephrotic syndrome receiving steroid therapy.

Methods: Thirty children with nephrotic syndrome were included in this study. After obtaining blood samples to measure $25(\mathrm{OH})$ D levels, all patients were supplemented with daily doses of Vitamin D for one month. Serum 25(OH) D level was checked again, and these patients were supplemented for another month if they had been recognized with deficiency at the last check. Results: Out of 30 children, $60 \%$ were male and $40 \%$ were female with a mean age of $6.91 \pm$ 3.34 years. Before intervention, $70 \%$ of patients had severe vitamin D deficiency, and $26.7 \%$ had mild to moderate deficiency, and none of the patients had normal serum levels of 25-(OH)-D. After one month, only one patient gained normal levels which was not statistically significant $(P=0.500)$. After two months of intervention, 12 patients escaped deficiency but still exhibited insufficient levels followed by 8 people with deficiency, and 10 patients reached normal values which was statistically significant $(P=0.002)$. The mean level of $25(\mathrm{OH}) \mathrm{D}$ was $8.277 \pm 0.84 \mathrm{ng} /$ $\mathrm{mL}$ rising to $14.364 \pm 1.14 \mathrm{ng} / \mathrm{mL}$ after two months $(P=0.001)$.

Conclusion: This study showed a high incidence of vitamin $D$ deficiency in the children with nephrotic syndrome warranting routine surveillance of vitamin D serum levels in these patients. Daily doses of vitamin D in the first month of onset of the disease was insufficient. We suggest that children may benefit from routine measurement of their serum vitamin D from diagnosis and later in follow-up visits so an individual strategy for vitamin D supplementation could be given.

Keywords: Nephrotic syndrome, Serum vitamin D3 level, Glucocorticoids, Vitamin D supplementation
\end{abstract}

Please cite this article as follows: Mahmoodzadeh $\mathrm{H}$, Valizadeh $\mathrm{M}$,

Nikibakhsh A, Abbasi E. Effects of supplementary vitamin $\mathrm{D}$ on vitamin D3 serum level in nephrotic syndrome patients receiving steroid therapy. Int J Basic Sci Med. 2020;5(4):142146. doi:10.34172/ ijbms.2020.25.

\section{Introduction}

Nephrotic syndrome is characterized by massive proteinuria, hypoalbuminemia, diffused edema, and hyperlipidemia. ${ }^{1,2}$ Nephrotic syndrome in children is usually diagnosed as a minimal change disease that is improved in $95 \%$ of cases by immunosuppressive therapy.,4 However, some children may develop steroid resistant nephrotic syndrome with long-term severe proteinuria and possible end-stage renal disease requiring renal replacement therapy. ${ }^{5}$ Adverse effects in nephrotic syndrome may be part of the disease itself or follow therapies introduced to the patient. Hypovitaminosis-D in patients with nephrotic syndrome is, in part, due to loss of vitamin $\mathrm{D}_{3}$ binding protein occurring in urinary excretion. ${ }^{6}$ This would result in decreased gastrointestinal calcium absorption leading to hypocalcemia and increased levels of parathyroid hormone (PTH) and phosphorus levels which, in turn, lead to increased osteoclast activity and decreased bone mineral density after initiation of glucocorticoid treatment and

(C) 2020 The Author(s); Published by Zabol University of Medical Sciences. This is an open-access article distributed under the terms of the Creative Commons Attribution License (http://creativecommons.org/licenses/by/4.0), which permits unrestricted use, distribution, and reproduction in any medium, provided the original work is properly cited. 
urinary calcium excretion. ${ }^{7}$ Introduction of corticosteroids would result in osteopenia, osteoporosis, and negative calcium balance. ${ }^{8}$ Therefore, both nephrotic syndrome and related. treatments would result in decreased vitamin- $\mathrm{D}_{3}$ levels and lower bone mineral density. ${ }^{9-12}$ National Kidney Foundation (NFK) guidelines have no definite protocol for serum vitamin $D_{3}$ measurement in patients with nephrotic syndrome and normal GFR (glomerular filtration rate). However, in patients with a high level of PTH and a GFR less than $60 \mathrm{~mL} / \mathrm{min}$, NFK has a recommended routine measurement of the serum level of 25-hydroxy vitamin $\mathrm{D}_{3}$ and supplementation with vitamin $\mathrm{D}_{3}$ in cases with levels less than $30 \mathrm{ng} / \mathrm{mL} .^{8}$ There are no protocols for prevention of glucocorticoidrelated bone adverse effects in children. ${ }^{12}$ In this study, we assessed the effect of the supplementary use of vitamin $\mathrm{D}$ on the serum level of vitamin D3 in patients with nephrotic syndrome receiving steroid therapy.

\section{Materials and Methods}

\section{Subjects}

This was a prospective clinical trial, and in this quasiexperimental study a cohort of 30 consecutive children with nephrotic syndrome (18 new cases and 12 with relapse) were enrolled at the Motahari teaching hospital (Urmia, 2015-2016).

\section{Inclusion and Exclusion criteria}

Inclusion criteria were age of $<5$ years and established nephrotic syndrome. Exclusion criteria were GFR less than $60 \mathrm{~mL} / \mathrm{min}$ according to the Schwarz formula, relapse of nephrotic syndrome in the past six months, taking corticosteroids and anticonvulsants or vitamin D preparations in the past six months, phosphorus levels of higher than $7 \mathrm{mg} / \mathrm{dL}$, and calcium levels of higher than 11 or less than $8 \mathrm{mg} / \mathrm{dL}$. All parents signed informed consent forms.

\section{Sample Size and Grouping of Subjects}

We set 2-sided $a$ of 0.05 and power of $80 \%$, and sample size in each group was calculated to be 10 according to the formula: $n=\frac{\left(z_{1-\alpha / 2}+z_{1-\beta}\right)^{2} \times\left(s_{1}{ }^{2}+s_{2}{ }^{2}\right)}{d^{2}}$; where, $\mu_{1,}, s_{1}{ }^{2}$ and $\mu_{2,}, s_{2}{ }^{2}$ are means and variances of the two groups, respectively, and $d^{2}=\left(\mu^{1}-\mu^{2}\right)^{2}$. It should be noted that this data was obtained from a previous study. ${ }^{4}$

\section{Vitamin D measurement}

The baseline serum level of 25-hydroxy vitamin- $\mathrm{D}_{3}$ was assessed by ichroma ${ }^{\mathrm{m}}$ Vitamin D kit and accordingly the patients were assigned into four groups: (1) severe deficiency: subjects with the serum level of vitamin- $\mathrm{D}_{3}$ less than $10 \mathrm{ng} / \mathrm{mL}$, (2) mild to moderate deficiency: subjects with the serum level of vitamin- $\mathrm{D}_{3}$ between 10 and $20 \mathrm{ng} / \mathrm{mL}$, (3) insufficient; subjects with the serum level of vitamin- $\mathrm{D}_{3}$ between 20 and $30 \mathrm{ng} / \mathrm{mL}$, and (4) normal: subjects with the serum levels of more than 30 $\mathrm{ng} / \mathrm{mL}$. All laboratory assessments were done in a single lab by chemiluminescence immunoassay.

\section{Vitamin D Supplementation}

Patients received prednisolone $60 \mathrm{mg} / \mathrm{m}^{2} / \mathrm{d}$ tablets accompanied by a preparation of vitamin $\mathrm{D}_{3}$ (called $\mathrm{D}_{3}$ FORT) 800-1200 u/day in those with deficiency followed by rechecking serum levels of $25(\mathrm{OH})$ vitamin $\mathrm{D}_{3}$. Then they received a $40 \mathrm{mg} / \mathrm{m}^{2} / \mathrm{d}$ tablet every other day, with vitamin $\mathrm{D}$ supplementation in those with persistent deficiency, followed by determining serum levels of vitamin $\mathrm{D}_{3}$ at the end of the month.

\section{Statistical analysis}

Data analysis was performed using SPSS (version 19.0) software [Statistical Procedures for Social Sciences; Chicago, Illinois, USA]. Repeated-measure analysis of variance (ANOVA), Bonferroni, Wilcoxon, and McNemar's tests were used, and $P$ values less than 0.05 were considered statistically significant. Mean levels of vitamin $\mathrm{D}$ after intervention and in the three times in all groups were analyzed by one-way ANOVA and repeated measures, respectively. McNemar's test was also used for comparing mean levels of vitamin D in one group, before and after intervention. The Friedman test was used to compare the frequency of different severities of vitamin D deficiency, (e.g., severe deficiency, moderate deficiency, inadequate and normal) at three different endpoints.

Results

\section{Subjects' Features}

Thirty consecutive children with nephritic syndrome were assigned in this study with a mean age of $6.91 \pm 3.34$ ranging from 2 to 14 years old. Eighteen cases (60\%) were male. The mean ages were $7.09 \pm 3.20$ and $6.65 \pm 3.67$ years in males and females, respectively $(P=0.728)$. There were no statistically significant relationships between sex and age of onset (either newly diagnosed or relapse) and serum levels of vitamin D. At the beginning of the study, $70 \%$ of patients $(n=21)$ had severe vitamin D deficiency, 26.7\% $(\mathrm{n}=8)$ had moderate vitamin D deficiency, and $3.3 \%(\mathrm{n}=1)$ had insufficient vitamin $\mathrm{D}$.

\section{Serum Levels of Vitamin D in Newly Onset Nephrotic} Syndrome and Relapsed Patients After Intervention

Sixty percent of patients had newly onset nephrotic syndrome and the rest were those who relapsed. The mean changes in serum levels of vitamin $\mathrm{D}$ after two months of intervention were $21.55 \mathrm{ng} / \mathrm{mL}$ and $16.45 \mathrm{ng} /$ $\mathrm{mL}$ for cases with first and recurrent attacks, respectively, and according to the independent samples $t$ test, the 
difference was statistically insignificant $(P=0.34)$ (Figure $1)$.

\section{Serum Levels of Vitamin D in Patients After Intervention} According to the Season

The mean changes in vitamin D two months after they received treatment according to the season have been shown in Figure 2. Overall, 30\% of the subjects were diagnosed in spring, $23.3 \%$ in summer, $20 \%$ in autumn, and $26.7 \%$ in winter. According to one-way ANOVA, the mean levels of vitamin $\mathrm{D}$ in different seasons were not significantly different $(P=0.196)$.

\section{Serum Levels of Vitamin D During Study (Beginning, 1 month, and 2 Months After Intervention)}

As shown in Figure 3, mean serum level of vitamin D before intervention was $8.27 \pm 0.84 \mathrm{ng} / \mathrm{mL}$, increasing to $14.36 \pm 1.14$ at one month and finally reaching $27.78 \pm$ 2.80 after two months of treatment $(P=0.001)$.

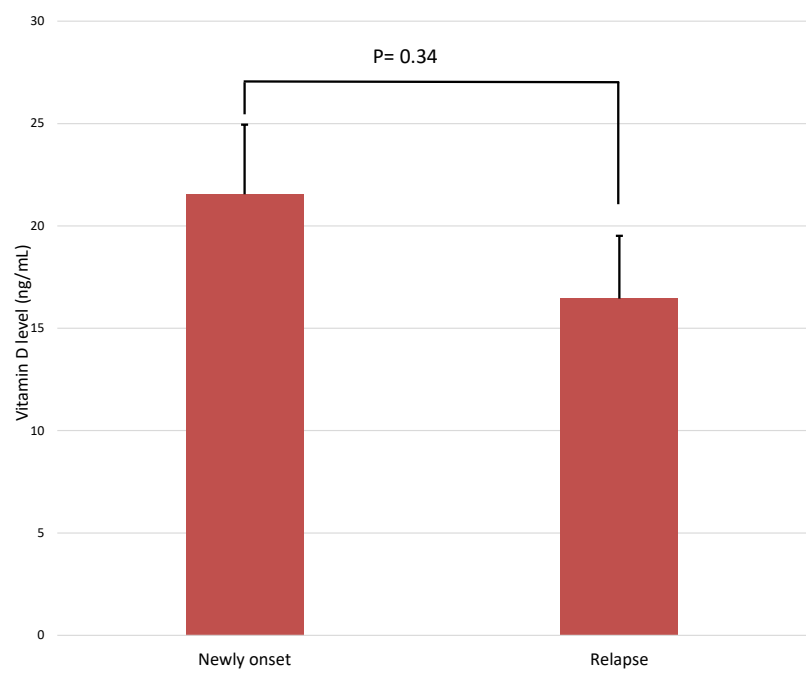

Figure 1. Mean End-of-Trial Serum Levels of Vitamin D in Two Groups of Patients.

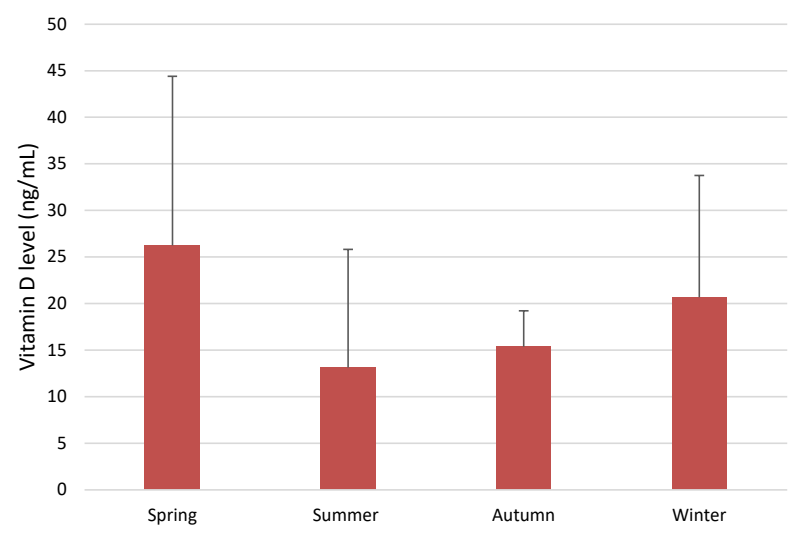

Figure 2. The Mean Levels of Vit D After 2 Months of Intervention According to the Season.

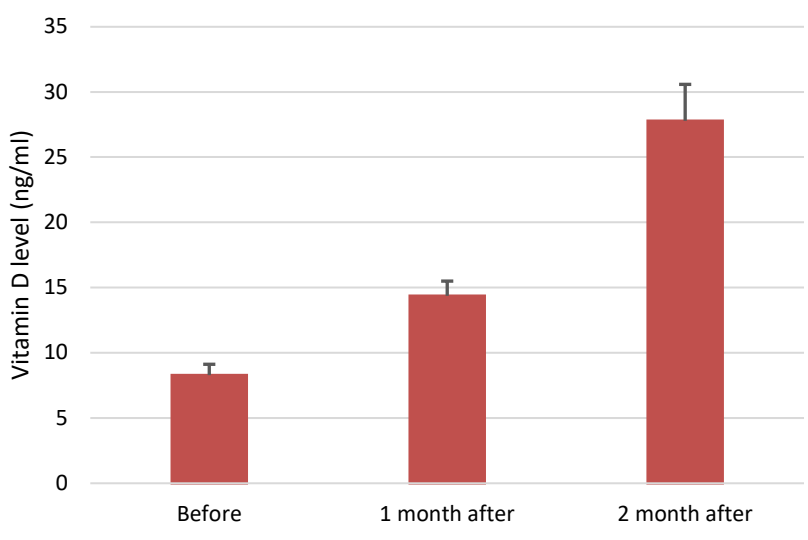

Figure 3. Serum Levels of Vitamin D During Study.

\section{Change of Serum Levels of Vitamin D After Treatment} According to Normal and Abnormal Levels

According to Table 1, 30 patients had abnormal serum levels of vitamin $\mathrm{D}$ at the beginning of the study (less than $30 \mathrm{ng} / \mathrm{mL}$ ), with only one patient reaching a normal value after one month of therapy $(P>0.05)$. Following two months of intervention, 10 patients reached normal levels $(P=0.001)$.

\section{Frequency of Different Grades of Vitamin D Deficiency in 3 Endpoints}

The Frideman test was used to compare the frequencies of different severities of vitamin D deficiency, (e.g., severe deficiency, moderate deficiency, inadequate, and normal) at three different endpoints. According to Table 2, at the beginning of the study, $70 \%$ of patients $(n=21)$ had severe vitamin D deficiency, followed by $26.7 \%(\mathrm{n}=8)$ with moderate vitamin D deficiency, and 3.3\% $(n=1)$ had insufficient vitamin D. One month after treatment, 16.7\% of patients $(\mathrm{n}=5)$ still suffered from severe deficiency, followed by $70 \%(\mathrm{n}=21)$ being moderately deficient, and only $10 \%(\mathrm{n}=3)$ experienced increased vitamin $\mathrm{D}$ serum levels. This was still insufficient with only one subject reaching normal value. Following two months of treatment, 3.3\% ( $\mathrm{n}=1), 23.3 \%(\mathrm{n}=7), 40 \%(\mathrm{n}=12)$, and $33.3 \%(n=10)$ of subjects were categorized as severe, moderate, insufficient, and normal, respectively.

\section{Discussion}

Nephrotic syndrome is a common glomerular disease in children, and they may experience some therapeutic adverse effects with the risk of metabolic bone disease. In different studies, the association between low serum vitamin $\mathrm{D}$ levels and decreased bone mineral density has been reported. ${ }^{1,9,11,13}$ Bone metabolic diseases, including osteoporosis, are common adverse effects of corticosteroid use. ${ }^{14}$ Vitamin D is a lipid-soluble steroid hormone available in different sources. ${ }^{15}$ The standards for vitamin D sufficiency in healthy children are not 
Table 1. Abnormal Serum Levels of Vitamin D During the Study

\begin{tabular}{lccc}
\hline & Normal & Abnormal & $P$ Value \\
\hline Time & 0 & 30 & \\
Baseline & 1 & 29 & 0.500 \\
1 Month after treatment & 10 & 20 & 0.001 \\
\hline
\end{tabular}

definitely defined; however, in children with deficiency, the radiological findings of rickets and decreased bone mineral density are reported in serum vitamin D levels between 16 and $18 \mathrm{ng} / \mathrm{mL}$. Increased alkaline phosphatase levels have been reported in serum vitamin $\mathrm{D}$ levels less than $20 \mathrm{ng} / \mathrm{mL}$. A majority of authors recommend maintaining serum vitamin $\mathrm{D}$ levels between 20 and 40 $\mathrm{ng} / \mathrm{mL}$ and some others recommend the range to be from 30 to $50 \mathrm{ng} / \mathrm{mL} .^{15}$

In our study, the prevalence of vitamin $\mathrm{D}$ deficiency in children with nephrotic syndrome was very high at $96.7 \%$, being higher than that of $87.8 \%$ in a study by Mahmoodzadeh et al. ${ }^{13}$ It is similar to those reported by Selewski et al, the United States, with the rate of $100 \% .{ }^{16}$ There are few studies about the effects of vitamin D supplementation on serum levels of this vitamin in children with nephrotic syndrome, and there is no recommendation by the NKF in this regard. In our study, daily administration of vitamin $\mathrm{D}$ though caused a rise in its serum levels but failed to attain normal values in all patients, which was in accordance with the reports of Zaniew and Jarmoliński, ${ }^{17}$ Selewski et al, ${ }^{16}$ and Haldimann \& Trechsel. $^{6}$ In the recent study, researchers reported normal vitamin $\mathrm{D}$ in 8 out of 9 patients after 8 weeks of therapy. ${ }^{6}$ However, in our study only one patient attained a normal vitamin D level at the end of the first month. This may be explained by patients taking different preparations of vitamin $\mathrm{D}$ in these two studies. There are different preparations of vitamin D. Vitamin D2 derivatives would normalize the serum level of vitamin $\mathrm{D}$ during 4 to 8 weeks but intoxication is relieved after 17 to 60 days post discontinuation. Normalization and detoxification for vitamin D3 derivatives is 2-4 weeks and 7 to 30 days, and 4 to 7 days and 2 to 10 days for calcitriol. ${ }^{18}$ For restoring the vitamin $\mathrm{D}$ resources in the body, the time required is 2-3-fold higher for vitamin D3 preparations compared to vitamin D2 derivatives. ${ }^{15}$
Interventional strategies are required to prevent bone diseases in patients with nephrotic syndrome, and the efficacies of different preparations have been compared in some studies. Chen et $\mathrm{al}^{18}$ reported the preferred form of vitamin $\mathrm{D}$ as calcitriol alone in comparison to calcium carbonate alone or their combination. They found no adverse effects in their study. Long-term vitamin D derivatives may reach normal levels more rapidly but intoxication is also more possible.

The main distinctive feature of this study was its prospective design, interventional type, and exclusion of confounding factors. This study has some limitations that may affect the results of our study. First, we only followed up subjects for 2 months, and second, the number of subjects used in this study was limited.

\section{Conclusion}

The present study showed high prevalence of vitamin D deficiency in children with nephrotic syndrome, warranting routine determination of serum levels of vitamin $\mathrm{D}$ in these patients. We suggest that children benefit from routine measurement of their vitamin $\mathrm{D}$ levels at the time of diagnosis, so an individual strategy for treatment with vitamin $\mathrm{D}$ can be given. We suggest implementing enrollment of control groups (healthy subjects with low vitamin D levels), having longer followup periods, and treatment with different vitamin D derivatives in future studies.

\section{Ethical Approval}

The Ethics Committee of Urmia University of Medical Sciences (code number: IR.UMSU.REC.1394.165), Urmia, Iran, approved this study undertaken in accordance with the principles of the Helsinki Declaration.

\section{Conflict of Interest Disclosure}

We declare that there is no conflict of interest.

\section{Authors' Contributions}

MV collected and analyzed the data, reviewed the literature and wrote the manuscript. HM supervised the study and data collection. AN supervised patient management and data collection. EA designed the study and supervised the whole process.

Table 2. Frequency of Different Grades of Vitamin D Deficiency in 3 Endpoints in 30 Children With Nephrotic Syndrome

\begin{tabular}{|c|c|c|c|c|c|}
\hline & Severe Deficiency & Mild-Moderate Deficiency & Insufficient & Normal & $P$ Value \\
\hline \multicolumn{6}{|l|}{ Time } \\
\hline Baseline & $21(70 \%)$ & $8(26 \%)$ & $1(4 \%)$ & $0(0 \%)$ & 0.001 \\
\hline 1 Month after treatment & $5(16 \%)$ & $21(70 \%)$ & $3(10 \%)$ & $1(4 \%)$ & 0.001 \\
\hline 2 Months after treatment & $1(4 \%)$ & $7(23 \%)$ & $12(40 \%)$ & $10(33 \%)$ & 0.001 \\
\hline
\end{tabular}




\section{References}

1. Ulinski T, Aoun B. Pediatric idiopathic nephrotic syndrome: treatment strategies in steroid dependent and steroid resistant forms. Curr Med Chem. 2010;17(9):847853. doi:10.2174/092986710790712174

2. Tapia C, Bashir K. Nephrotic syndrome. In: StatPearls. Treasure Island, FL: StatPearls Publishing LLC; 2020.

3. Vivarelli M, Massella L, Ruggiero B, Emma F. Minimal change disease. Clin J Am Soc Nephrol. 2017;12(2):332345. doi:10.2215/cjn.05000516

4. Lee JM, Kronbichler A, Shin JI, Oh J. Current understandings in treating children with steroid-resistant nephrotic syndrome. Pediatr Nephrol. 2021;36(4):747-761. doi:10.1007/s00467-020-04476-9

5. Park SJ, Shin JI. Complications of nephrotic syndrome. Korean J Pediatr. 2011;54(8):322-328. doi:10.3345/ kjp.2011.54.8.322

6. Haldimann B, Trechsel U. Vitamin D replacement therapy in patients with the nephrotic syndrome. Miner Electrolyte Metab. 1983;9(3):154-156.

7. Christakos S, Dhawan P, Porta A, Mady LJ, Seth T. Vitamin $\mathrm{D}$ and intestinal calcium absorption. Mol Cell Endocrinol. 2011;347(1-2):25-29. doi:10.1016/j.mce.2011.05.038

8. Weng FL, Shults J, Herskovitz RM, Zemel BS, Leonard MB. Vitamin D insufficiency in steroid-sensitive nephrotic syndrome in remission. Pediatr Nephrol. 2005;20(1):56-63. doi:10.1007/s00467-004-1694-7

9. Hahn D, Hodson EM, Willis NS, Craig JC. Corticosteroid therapy for nephrotic syndrome in children. Cochrane Database Syst Rev. 2015;2015(3):CD001533. doi:10.1002/14651858.CD001533.pub5

10. Goldstein DA, Oda Y, Kurokawa K, Massry SG. Blood levels of 25-hydroxyvitamin $\mathrm{D}$ in nephrotic syndrome. Studies in 26 patients. Ann Intern Med. 1977;87(6):664667. doi:10.7326/0003-4819-87-6-664
11. Jeon SH, Lim AY, Kim YK, et al. The effect of steroid therapy on growth and bone density in children with nephrotic syndrome. J Korean Pediatr Soc. 1998;41(10):1396-1402.

12. Choudhary S, Agarwal I, Seshadri MS. Calcium and vitamin $\mathrm{D}$ for osteoprotection in children with new-onset nephrotic syndrome treated with steroids: a prospective, randomized, controlled, interventional study. Pediatr Nephrol. 2014;29(6):1025-1032. doi:10.1007/s00467-0132720-4

13. Mahmoodzadeh $\mathrm{H}$, Nasimfar A, Sadeghi E, et al. Study of vitamin D level in children with non-specific musculoskeletal pain. Int J Pediatr. 2017;5(3):4533-4540. doi:10.22038/ijp.2016.20988.1756

14. Esmaeeili M, Azarfar A, Hoseinalizadeh S. Calcium and vitamin $\mathrm{d}$ metabolism in pediatric nephrotic syndrome; an update on the existing literature. Int J Pediatr. 2015;3(12):103-109. doi:10.22038/ijp.2015.3932

15. Hansen KE, Kleker B, Safdar N, Bartels CM. A systematic review and meta-analysis of glucocorticoid-induced osteoporosis in children. Semin Arthritis Rheum. 2014;44(1):47-54. doi:10.1016/j.semarthrit.2014.02.002

16. Selewski DT, Chen A, Shatat IF, et al. Vitamin D in incident nephrotic syndrome: a Midwest Pediatric Nephrology Consortium study. Pediatr Nephrol. 2016;31(3):465-472. doi:10.1007/s00467-015-3236-x

17. Zaniew M, Jarmoliński T. Vitamin D status and bone density in steroid-treated children with glomerulopathies: effect of cholecalciferol and calcium supplementation. Adv Med Sci. 2012;57(1):88-93. doi:10.2478/v10039-012-00168

18. Chen Y, Wan JX, Jiang DW, et al. Efficacy of calcitriol in treating glucocorticoidinduced osteoporosis in patients with nephrotic syndrome: an open-label, randomized controlled study. Clin Nephrol. 2015;84(5):262-269. doi:10.5414/cn108473 